\title{
Surgical outcomes of patients with early cervical cancer treated with radical hysterectomy in a tertiary care hospital
}

\author{
Rameshkumar R., Namrata Kulkarni*, Anuriti Sharma, Chaitra Kulkarni
}

Department of obstetrics and gynaecology, Shree Dharmasthala Manjunatheshwara College of Medical Sciences and Hospital, Dharwad, Karnataka, India

Received: 08 December 2020

Accepted: 22 January 2021

\section{*Correspondence:}

Dr. Namrata Kulkarni,

E-mail: namrata.r.kulkarni@gmail.com

Copyright: (c) the author(s), publisher and licensee Medip Academy. This is an open-access article distributed under the terms of the Creative Commons Attribution Non-Commercial License, which permits unrestricted non-commercial use, distribution, and reproduction in any medium, provided the original work is properly cited.

\begin{abstract}
Background: This study was undertaken to evaluate the surgical outcomes of patients with early cervical cancer treated with radical hysterectomy.

Methods: A total of 50 patients who underwent modified radical hysterectomy between April 2006 and April 2016 at Shri Dharmasthala Manjunatheswara medical college and hospital, Dharwad, Karnataka were retrospectively reviewed. The analysis included clinical and pathologic variables including age, tumour size, clinical stage, lymphovascular space involvement, tumour type and grade, lymph node metastases, surgical margin involvement, intraoperative and postoperative complications and pattern of adjuvant therapy were analysed.

Results: The median age of the patient who underwent radical hysterectomy was 47.8 years, the mean parity being 3.6. Histologically, the most common type of malignancy encountered was squamous cell carcinoma of the cervix, which occurred in 42 patients $(84 \%) .8(16 \%)$ showed involvement of 1 or more lymph nodes and evidence of lymphovascular invasion. Involvement of the resected vaginal margins was noted in 11 patients $(22 \%)$. The average hospital stay was 19.8 days, the prolonged stay resulting from postoperative morbidity. Postoperative concurrent chemoradiation with cisplatin was administered in eight $(16 \%)$ cases due to pelvic lymph node metastases. Postoperative vaginal brachytherapy was given in 11 (22\%) cases because of positive vaginal margins.

Conclusions: The present study shows that general gynaecologists with significant experience in general gynaecologic surgery may, with adequate but abbreviated training, become competent in performing a modified radical hysterectomy.
\end{abstract}

Keywords: Radical hysterectomy, Cervical cancer, Surgical management

\section{INTRODUCTION}

One woman dies of cervical cancer every 8 minutes in India. Cervical cancer is the second most common cancer in India in women accounting for $22.86 \%$ of all cancer cases in women, is the third largest cause of cancer mortality in India accounting for nearly $10 \%$ of all cancer related deaths in the country. ${ }^{1}$

Radical hysterectomy with pelvic lymphadenectomy is indicated for early invasive cervical cancer. International federation of gynaecology and obstetrics (FIGO) staging system has divided early invasive cervical cancer into stage IA1, which includes lesions invading the cervical stroma to a depth of $3 \mathrm{~mm}$, or less and a maximum horizontal spread of $7 \mathrm{~mm}$. Stage IA2 includes lesions with stromal invasion of $3-5 \mathrm{~mm}$ and a maximum horizontal spread of $7 \mathrm{~mm}^{2}$ Patients with stage IB1 cervical cancer have clinically visible cervical lesion $\leq 4.0$ $\mathrm{cm}$ diameter or microscopic evidence of stromal invasion $>5 \mathrm{~mm}$, horizontal spread $>7 \mathrm{~mm}$. 
Patients with FIGO stage IA1 cervical cancer and no evidence of lymph vascular space invasion (LVSI) are treated with cervical conization or simple hysterectomy. ${ }^{3}$ Patients with stage IA2 or Stage IB1 cervical cancer have a significant risk of lymph node metastasis, radical hysterectomy and pelvic lymphadenectomy is the treatment of choice. Patients with stage IB2 or stage IIA cervical cancer are treated by chemoradiation or combined therapy, although a few selected patients may undergo radical hysterectomy and pelvic lymphadenectomy. ${ }^{4}$

Complications of radical hysterectomy with lymphadenectomy include haemorrhage, infection, ureteral injury, bladder injury, blood vessel injury, urinary tract fistula, bladder dysfunction, pulmonary embolism, deep vein thrombosis, lympho-cysts and intestinal obstruction. With evolution of surgical technique and improved pre- and postoperative care, the frequency of complications due to radical hysterectomy have been decreasing. ${ }^{5}$ Hence, this study was undertaken to evaluate the surgical outcomes of patients with early cervical cancer treated with radical hysterectomy.

\section{METHODS}

This was a retrospective study conducted at Shri Dharmasthala Manjunatheswara medical college and hospital Dharwad from 2006 to 2016, in a total of 50 women with carcinoma cervix FIGO stage IA2, IB and IIA who underwent radical hysterectomy.

Women with an invasive cervical cancer tumour size greater than $4 \mathrm{~cm}$, FIGO stage IB2-IV, uterine size larger than $12 \mathrm{~cm}$, patients with a history of pelvic or abdominal radiotherapy; patients who were pregnant; patients with contraindications or unfit for surgery, patients with evidence of metastatic disease or enlarged pelvic or aortic lymph nodes (more than 2 centimetres) by conventional imaging studies were excluded from the study.

All women with early-stage cervical carcinoma underwent type III radical hysterectomy. The abdomen is opened using either a sub-umbilical midline incision or a low transverse (Maylard's) incision. The pelvis is thoroughly examined to identify obvious visceral and/or nodal spread. In the absence of obvious spread, the ureters are identified and dissected to the point of entry to the bladder. Hysterectomy is performed, the uterine arteries are ligated at its origin where it branches off the hypogastric artery and the medial halves of the cardinal ligaments and the proximal uterosacral ligaments are removed. A cuff of vagina (usually about $2 \mathrm{~cm}$ ) is removed, and a complete pelvic lymphadenectomy is performed. Postoperatively, patients are given broad spectrum antibiotics and prophylaxis for venous thromboembolism. The urinary catheter is retained for 10 days. Patients are discharged when they are fully ambulant and can tolerate a normal diet and have normal bladder habits. Postoperative review occurs between 2 and 4 weeks later with the results of histopathology; subsequent follow-up is performed at regular intervals in the outpatient department.

The ethical clearance was obtained from institutional review board. Using a predefined data collection form, all clinical, operative and pathological variables were retrospectively collected from medical records.

\section{RESULTS}

A total of 50 radical hysterectomies were performed at Shri Dharmasthala Manjunatheswara medical college and hospital, Dharwad between January 2006 to December 2016. The median age of the patient who underwent radical hysterectomy was 47.8 years, the mean parity being 3.6.

Out of the 50 patients, $18(36 \%)$ had stage IA1 cervical carcinoma, $4(8 \%)$ had stage 1A2, 12(24\%) had stage $1 \mathrm{~B} 1,10(20 \%)$ had stage $1 \mathrm{~B} 2$ and $6(12 \%)$ were diagnosed with stage $2 \mathrm{~A}$ cervical carcinoma. 15 (30\%) patients had a midline vertical incision, whereas in $35(70 \%)$ a Pfannestiel or a Maylard's incision was used. The mean duration of surgery was 250 minutes, the mean being 270 minutes in the patients with midline vertical scar and 230 minutes in patients who had a Pfannenstiel scar. The mean blood loss was 950 millilitres, the blood loss being same in the patients with midline and pfannenstiel incision (Table 1).

Table 1: Clinical variables of patients with early cervical cancer.

\begin{tabular}{|lll|}
\hline Clinical variables & & N $(\%)$ \\
\hline Age (years) & Mean \pm SD & $47.8 \pm 7.1$ \\
\hline Parity & Mean \pm SD & $3.6 \pm 1.23$ \\
\hline \multirow{3}{*}{ Stage } & 1A1 & $18(36)$ \\
\cline { 2 - 3 } & 1A2 & $04(8)$ \\
& 1B1 & $12(24)$ \\
\hline 1B2 & $10(20)$ \\
\cline { 2 - 3 } Type of incision & Maylard's & $06(12)$ \\
\hline $\begin{array}{l}\text { Mean duration of } \\
\text { surgery }\end{array}$ & Midline vertical & $35(70)$ \\
\hline
\end{tabular}

Procedural complications were seen in $6(12 \%)$ patients. Intraoperative complications include: 1 (2\%) case of bladder injury, $3(6 \%)$ cases of ureteric injury, bowel injury occurred in $1(2 \%)$ patient and $1(2 \%)$ patient had great vessel injury. Postoperative complications included one $(2 \%)$ case of bladder dysfunction, infectious morbidity occurred in $20(40 \%)$ patients, wound infection accounting for $12(24 \%)$ cases and urinary tract infection occurred in $8(16 \%)$ cases. $22(44 \%)$ patients received blood transfusion. $1(2 \%)$ subject had deep vein thrombosis (DVT) and another had pulmonary embolism (PE) requiring intensive care. There were no cases of acute ileus or lymphocyte formation (Table 2). 
Table 2: Perioperative complications in radical hysterectomy patients.

\begin{tabular}{|ll|}
\hline Complications & No. of cases $(\%)$ \\
\hline Intra-operative complications & \\
\hline Mean blood loss (ml) & 950 \\
\hline Bladder/ureter injury & $4(8)$ \\
\hline Vascular injury & $1(2)$ \\
\hline Bowel injury & $1(2)$ \\
\hline Post-operative complications & \\
\hline Bladder dysfunction & $1(2)$ \\
\hline Wound infection & $12(24)$ \\
\hline Urinary tract infection & $8(16)$ \\
\hline Blood transfusion & $22(44)$ \\
\hline DVT/PE & $02(4)$ \\
\hline Hospital stays (mean in days) & 19.8 \\
\hline
\end{tabular}

Histologically, the most common type of malignancy encountered was squamous cell carcinoma of the cervix, which occurred in 42 patients $(84 \%)$. Of the remaining patients, $5(10 \%)$ had adenocarcinoma of the cervix, 2 (4\%) had adenoid basal carcinoma, 1 (2\%) had clear cell cervical carcinoma. However, in a case of adenocarcinoma, the point of origin (endocervical vs endometrial) was not precisely elucidated. In addition, 10 patients were found to have cervical intraepithelial neoplasia (CIN) grade 3/in-situ carcinoma (Table 3).

Table 3: Histopathological variables in patients with early invasive carcinoma.

\begin{tabular}{|lll|}
\hline Variables & Squamous cell & N $(\%)$ \\
\hline Cell type & $\begin{array}{l}\text { Sqrcinoma } \\
\text { Adenocarcinoma }\end{array}$ & $42(84)$ \\
\hline & $\begin{array}{l}\text { Adenoid basal } \\
\text { carcinoma }\end{array}$ & $02(10)$ \\
\hline $\begin{array}{l}\text { Clear cell } \\
\text { carcinoma }\end{array}$ & $01(2)$ \\
\hline LVSI & Positive & $08(16)$ \\
\hline $\begin{array}{l}\text { Vaginal margin } \\
\text { status }\end{array}$ & Negative & $42(84)$ \\
\hline $\begin{array}{l}\text { Lymph node } \\
\text { status }\end{array}$ & Negative & $11(22)$ \\
\hline
\end{tabular}

Of the 50 patients, $8(16 \%)$ showed involvement of 1 or more lymph nodes and evidence of lymphovascular invasion. Involvement of the resected vaginal margins was noted in 11 patients $(22 \%)$. The average hospital stay was 19.8 days, the prolonged stay resulting from postoperative morbidity.

Postoperative concurrent chemoradiation with cisplatin was administered in eight $(16 \%)$ cases due to pelvic lymph node metastases. Postoperative vaginal brachytherapy was given in $11(22 \%)$ cases because of positive vaginal margins.

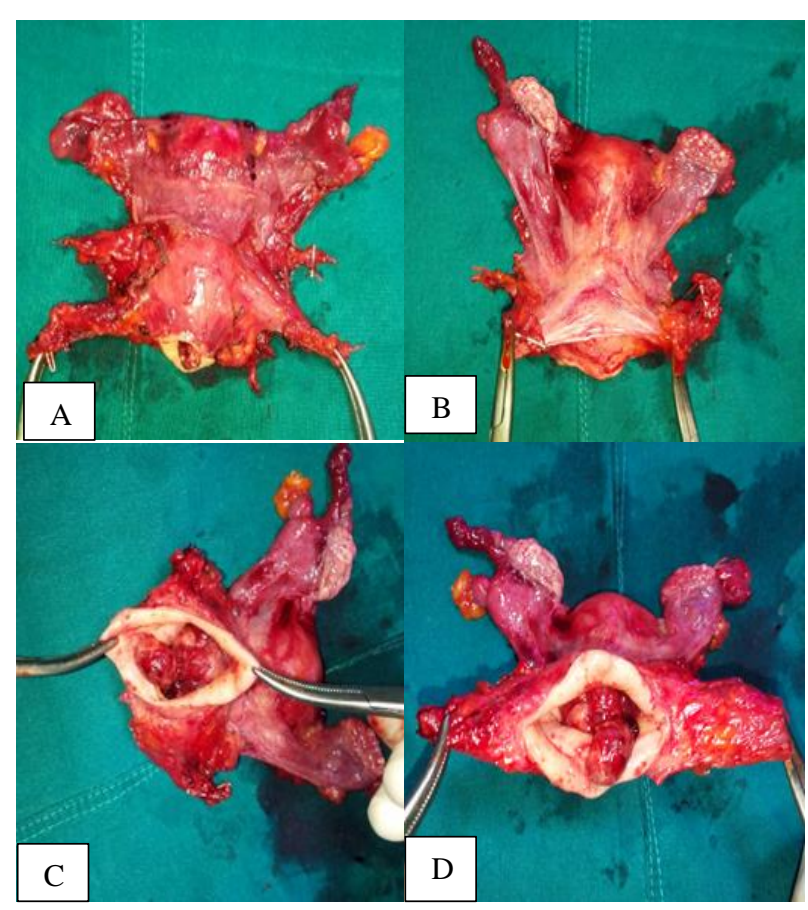

Figure 1: Surgical treatment. (A) extent of parametrium excised (B) uterosacral dissection (C) vaginal margins $(\mathrm{D})$ parametrium and vaginal margins (cervical growth visible).

\section{DISCUSSION}

Radical (Wertheim) hysterectomy is a surgically demanding procedure, and is performed almost exclusively by gynaecologic oncologists in resource-rich countries. However, in low-income countries where the prevalence of cervical cancer is higher, it continues to be performed by general gynaecologists. At SDM Medical College Hospital, only 4 of the gynaecologists were trained to perform type III radical hysterectomy. Radical hysterectomy is not a common procedure at our institute, a total of 50 radical hysterectomies were performed over the 10-year period of the present review. In comparison, over 240 simple hysterectomies are performed at this institution each year.

The present study reflects the preference for the Maylard's incision for better exposure and access, as the majority of procedures $(70 \%)$ were performed using this method. The mean duration of the surgery was 250 minutes, which is comparable to previously published data. ${ }^{6}$ Use of a Maylard's incision was associated with a significant reduction in the duration of operation, as well as reduced hospital stay.

The type of incision did not make any difference in terms of blood loss during surgery, the mean blood loss in our study being $950 \mathrm{ml}$. The average blood loss with midline vertical incision was 920 and $1050 \mathrm{ml}$ with Maylard's incision. Our results correlate with the other studies, the mean blood loss reported ranging between $800 \mathrm{~mL}$ and $1000 \mathrm{~mL}$ in other centres. ${ }^{7,8}$ 
The operative complications encountered were not unexpected, with ureteric injury occurring in 3 patients $(6 \%)$, there was a solitary case of postoperative fistula formation, gives a rate of $2 \%$ who required a percutaneous nephrostomy and Boari flap repair at a later date. Previous publications have found the rate of ureteric injury at the time of radical hysterectomy to be up to approximately $2.5 \%$, and a high rate of $10 \%$ reported in one series. ${ }^{9,10}$

There was a case of great vessel injury (external iliac vein) accounting to $2 \%$ comparable to study reported by Cai et al which were repaired with the help of vascular surgeon. ${ }^{11}$ A solitary case of rectal injury was noted in this case series.

The most frequent postoperative complication reported in the literature is bladder dysfunction, occurring in 10 to $50 \%$ of cases. ${ }^{12}$ In our series, bladder dysfunction occurred in 1 patient $(2 \%)$. This decrease in the rate of bladder dysfunction may have been due to smaller injuries to the nervous plexuses related to the bladder, which were extensively sectioned in the past and prolonged postoperative bladder catheterization for 10 days. Postoperative infectious resulted in morbidity in $40 \%$ patients. Urinary tract infection was seen in $16 \%$ and wound infection accounted for $24 \%$ of cases, comparable to studies by Cai and Pikaart. ${ }^{11,13}$

Histologically, the malignancy noted in $84 \%$ of the radical hysterectomies performed was confirmed to be squamous cell carcinoma of the cervix. This was followed by cervical adenocarcinoma and adenosquamous carcinoma of the cervix, at 10 and $4 \%$, respectively. Other types of malignancy are uncommon, clear cell carcinoma accounting for $2 \%$ of all cervical cancers. A multivariate analysis describes lymph node (LN) status, histopathologic parametrial invasion, lymphvascular space invasion (LVSI), and histology of pure adenocarcinoma to be independently related to patients' poor survival. For patients with tumour histologically confined to the cervix, no parametrial invasion or lymph node metastasis, LVSI was the most important prognostic factor, and histologic type, depth of cervical stromal invasion, and tumour size are not related to survival. ${ }^{14}$

The clinical staging of cervical cancer, for the purpose of determining the primary method of treatment, was accurate in 31 of the 50 surgeries performed for cervical pathology (78\%); the other 19 cases showed histologic evidence of nodal or vaginal margin involvement, and therefore required treatment corresponding to a more advanced disease stage (i.e., adjuvant chemotherapy/radiotherapy). This result is reasonable because previous reports have shown an accurate correlation between clinical staging and postoperative histologic findings of about $61 \%{ }^{15}$

The key limitation of the study was retrospective study design and data retrieved from the old existing records.
The study was single centred and our sample size also limited the external validity of the study. Future studies must include large sample size follow up studies to increase the validity of the study findings.

\section{CONCLUSION}

Radical hysterectomy with pelvic lymphadenectomy is the treatment of choice for healthy women with stage IA2-IB1 cervical carcinoma. Women with non-bulky IB2 and IIA cervical carcinoma, may also be considered for surgical treatment by radical hysterectomy. Improvements in surgical technique, prophylactic antibiotics, thromboembolic prophylaxis, administration of blood products, and advances in postoperative and critical care medicine all have lowered operative morbidity from this procedure. Five-year survival rates in excess of $90 \%$ can be achieved when this procedure is performed for the proper indications. The present study shows that general gynaecologists with significant experience in general gynaecologic surgery may, with adequate but abbreviated training, become competent in performing a modified radical hysterectomy, with outcomes comparable to those seen in high income countries.

\section{Funding: No funding sources \\ Conflict of interest: None declared \\ Ethical approval: The study was approved by the Institutional Ethics Committee}

\section{REFERENCES}

1. National Cancer Registry Programme, Globocan 2012. Available at: http://www.globocan.iarc.fr. Accessed 20 Nov 2020.

2. Pecorelli S. Revised FIGO staging for carcinoma of the vulva, cervix, and endometrium. Int J Gynaecol Obstetr. 2009;105(2):103-4.

3. Sevin BU, Nadji M, Averette HE, Hilsenbeck S, Smith D, Lampe B. Microinvasive carcinoma of the cervix. Cancer. 1992;70(8):2121-8.

4. Michalas S, Rodolakis A, Voulgaris Z, Vlachos G, Giannakoulis N, Diakomanolis E. Management of early-stage cervical carcinoma by modified (type II) radical hysterectomy. Gynecol Oncol. 2002;85(3):415-22.

5. Ayhan A, Tuncer ZS, Yarali H. Complications of radical hysterectomy in women with early-stage cervical cancer: clinical analysis of 270 cases. Eur J Surg Oncol. 1991;17:492-4.

6. Powell JL, Ross SC, Henderson GS. Radical hysterectomy and pelvic lymphadenectomy at a community teaching hospital. J Gynecol Surg. 2003;19(3):129-31.

7. Olatunji AO, Adefuye PO, Jagun EO, Oloruntoba AR. Radical (Wertheim) hysterectomy for early stage (1B and $2 \mathrm{~A})$ cancer of the cervix. Niger Med Pract. 2006;50(2):33-5. 
8. Gharoro EP. Surgical management of early stages of cervical cancer: the value of internal iliac artery ligation. J Obstet Gynaecol. 2003;23(1):44-7.

9. Yuvaraja TB, Wuntakal R, Maheshwari A, Kerkar RA, Tongaonkar HB. Management and long-term follow-up of ureteric injuries during radical hysterectomy: single center experience. J Gynecol Surg. 2003;19(3):133-9.

10. Likic IS, Kadija S, Ladjevic NG, Stefanovic A, Jeremic K, Petkovic S et al. Analysis of urologic complications after radical hysterectomy. Am J Obstet Gynecol. 2008;199(6):644.

11. Cai H-B, Chen H-Z, Zhou Y-F, Lie D-M, Hou H-Y. Class II radical hysterectomy in low-risk ib squamous cell carcinoma of cervix: a safe and effective option. Int $\mathrm{J}$ Gynecol Cancer. 2009;19(1):46-9.

12. Ayhan A, Tuncer ZS, Yarali H. Complications of radical hysterectomy in women with early-stage cervical cancer: clinical analysis of 270 cases. Eur J Surg Oncol.1991;17:492-4.
13. Pikaart DP, Holloway RW, Ahmad S. Clinicalpathologic and morbidity analyses of types 2 and 3 abdominal radical hysterectomy for cervical cancer. Gynecol Oncol. 2007;107(2):205-10.

14. Takeda N, Sakuragi N, Takeda M, Okamoto K, Kuwabara M, Negishi $\mathrm{H}$ et al. Multivariate analysis of histopathologic prognostic factors for invasive cervical cancer treated with radical hysterectomy and systematic retroperitoneal lymphadenectomy. Acta Obstet Gynecol Scand. 2002;81(12):1144-51.

15. Ackermann S, Beckmann M. Accuracy of cervical cancer staging needs improvement. Am J Obstet Gynecol 2005;192(2):659-60.

Cite this article as: Rameshkumar R, Kulkarni N, Sharma A, Kulkarni C. Surgical outcomes of patients with early cervical cancer treated with radical hysterectomy in a tertiary care hospital. Int J Reprod Contracept Obstet Gynecol 2021;10:960-4. 